\section{LA CUESTIÓN DE LA MORAL EN SER Y TIEMPO DE MARTIN HEIDEGGER}

\author{
Vicente Lozano Díaz \\ Universidad Francisco de Vitoria \\ v.lozano@ufv.es
}

\section{THE QUESTION OF ETHICS IN MARTIN HEIDEGGER'S BEING AND TIME}

Cómo citar este artículo/Citation: Lozano Díaz, V. (2015). "La cuestión de la moral en Ser y tiempo de Martin Heidegger". Arbor, 191 (774): a255. doi: http://dx.doi.org/10.3989/ arbor.2015.774n 4010
Copyright: (c) 2015 CSIC. Este es un artículo de acceso abierto distribuido bajo los términos de la licencia Creative Commons Attribution-Non Commercial (by-nc) Spain 3.0.
RESUMEN: Se puede ver en Ser y tiempo el intento de establecer una moral de la autenticidad, pues la vida humana se considera como constante proyectarse hacia adelante, estableciendo metas e intentando cumplirlas a partir de la decisión y de la responsabilidad que surge de la propia comprensión de uno mismo como proyecto individual e intransferible. Pero esta moral de la autenticidad solo sería aceptable para Heidegger si se considerase como fundamento ontológico o metafísico independiente de las verdades, valores o principios que a su vez se utilizarían como criterios para las conductas o comportamientos concretos.

PALABRAS CLAVE: Ser; ente; respectividad; proyecto; muerte; responsabilidad; decisión; autenticidad; moral.
ABSTRACT: In Being and Time one can perceive an attempt to establish an ethics of authenticity, as human life is described as a constant endeavour to move forward, establishing goals and striving to achieve them based on decisions and a sense of responsibility grounded in one's understanding of oneself as an individual and a non-transferable project. But these ethics of authenticity would only be acceptable to Heidegger if considered as an ontological or metaphysical foundation independent from the truths, values or principles which, in turn, are used as criteria for specific conducts and behaviours.

KEYWORDS: Being; entity; respectivity; project; death; responsibility; decision; authenticity; ethics. 


\section{LA PREGUNTA POR EL SER COMO BÚSQUEDA DE LO ORIGINARIO}

En cuanto que miembro del movimiento fenomenológico iniciado por su maestro Husserl, Heidegger plantea su primera obra importante, Ser y Tiempo, publicada en 1927, como una búsqueda de la estructura originaria de la realidad misma. Sin embargo, y a diferencia de Husserl, no buscará esta dimensión originaria en el yo trascendental o conciencia pura de la que participa todo yo o conciencia subjetiva individual humana, y que constituye el mundo y los objetos que luego se encuentran los sujetos humanos individuales. Huyendo de todo intelectualismo, Heidegger considera que la estructura originaria de la realidad está escondida o disimulada por los hechos cotidianos y banales que nos envuelven, nos implican y nos absorben, y que por ello el punto de partida en su búsqueda tiene que ser un análisis de la actividad práctica de la vida humana que vaya más allá de nuestras representaciones inmediatas. Lo primario que se trata de entender no será accesible desde los conocimientos de un sujeto acerca de los objetos, ni siquiera desde los actos del sujeto sobre los objetos, sino desde los comportamientos del sujeto, que incluyen tanto a los objetos como a lo que el propio sujeto experimenta en sí mismo. Comportamientos del sujeto que son previos u originales respecto a la posterior nivelación que producen las categorías objetivantes de la teoría y de la razón.

Si para Husserl la fenomenología era fundamentalmente mirada reflexiva, un acto de conciencia descriptivo, ahora el análisis fenomenológico es fundamentalmente comprensión hermenéutica, un comportamiento o cierto tipo de experiencia personal (Von Herrmann, 2000, pp. 3-5, 31-32, 79-82 y 146148). Lo que vemos y comprendemos no son simplemente objetos a los que hemos dado un sentido como tales, a los que hemos constituido, sino experiencias vitales en sí mismas que están aconteciendo y que están siendo hechas explícitas y visibles. Todo lo cual adopta en Ser y Tiempo la forma de la pregunta por el Ser, la pregunta por el sentido de aquello que determina a los seres como seres y hace posible que sean entendidos, la pregunta por el sentido de la capacidad de encontrar sentido a todo lo que existe.

Heidegger comienza distinguiendo entre Ser (Sein) y ente (Seiend). Ser es lo que determina al ente en cuanto ente, lo que hace que un ente sea, y ente significa cosa, algo que es. El ente o cosa es "lo que" es, mientras que el Ser es lo que hace posible a todo "qué", lo que puede aplicarse a cualquier ente o cosa.
Por ello, todo ente presupone el Ser, que no puede ser pensado como un ente más, como una cosa o un objeto, sino que es una especie de horizonte significativo desde el cual toda realidad, todo ente, es siempre visto. Ser es pues la idea no captada conceptualmente que la metafísica supone sin tematizar. Es una idea indefinida de la que no tenemos en principio ningún contenido que la precise, pero que está actuando desde el momento en que hay entes, cosas que son (Rodríguez, 1987, p. 60). Es un significado anterior a todas las distinciones que la tradición ha efectuado sobre los entes y que han dado lugar a las diferentes ciencias o saberes. Primero los entes son, tienen ser, las cosas existen, y presuponiendo esto, las diferentes ciencias acotan un ámbito del Ser, un grupo de entes, y los estudia. Así, la física estudia los entes o cosas que se hallan presentes en la naturaleza, la matemática estudia los entes o cosas que se conocen como números, la historia estudia cómo se han comportado o qué le ha sucedido a un grupo de entes llamados seres humanos, etc.

\section{EL SER-AHÍ Y SU REALIDAD}

Heidegger añade además que el Ser solo será abordable si partimos del ser humano, único ente que se pregunta por el Ser. Todos los entes o cosas son, tienen ser, pero solo un grupo de entes, los seres humanos, preguntamos por el Ser, y ello indica que tenemos una cierta precomprensión de él, una comprensión confusa y poco clara, ya que preguntamos por el Ser sin que acabemos de ver exactamente por lo que preguntamos, pero real, pues en caso contrario no podríamos ni tan siquiera hacernos la pregunta (Heidegger, 2003, pp. 28-29).

El ser humano es, dice Heidegger, ser-ahí (Dasein), único ente que entiende el Ser, que ve su vida afectada por el Ser, que existe (Existenz), mientras que los demás entes simplemente son o subsisten, están meramente presentes (Vorhandenheit) o son manejables (Zuhandenheit). La distinción entre el Ser y el ente pertenece así al modo de existir del ser-ahí, sea o no este explícitamente consciente de ello. De hecho puede decirse que existir es estar llevando a cabo dicha distinción, aunque sea de una manera latente. $Y$ lo que tiene que hacerse para concebir expresamente esta distinción, para intentar alcanzar un conocimiento lo más claro y preciso del Ser, es analizar ese rasgo especial del ser humano o ser-ahí, aclarar la vaga comprensión que posee del Ser. Se trata de distinguir entre lo existentivo (existenziell) u óntico del ser humano, aquellas propiedades o aspectos que posee en 
cuanto es un ente más, y lo existencial (existenzial) u ontológico, aquellos elementos que se refieren al ser humano en tanto condicionado por su comprensión del Ser, aquello que lo convierte en un ser-ahí.

El ser-ahí no es el ser humano sin más, sino que es lo originario del ser humano, es el ser humano en tanto que se relaciona con el Ser, que se encuentra en la comprensión del Ser. Comprensión que hace de enlace entre la cuestión del Ser y la intrínseca finitud de ese ser humano que es propenso a ella. Más que un mero sinónimo de ser humano, el ser-ahí es un acontecer o un dirigirse hacia que tiene lugar en el ser humano (Richardson, 1967, p. 45). El ser-ahí no es algo dado empíricamente, no puede confundirse con un existente concreto, sino que es la condición de posibilidad de toda existencia concreta.

El propio Heidegger indica que si se parte del ser humano tiende a considerársele como un yo o un sujeto inmediatamente dado y se tiende a obviar la pregunta por su ser, por lo ontológico originario. Motivo por el cual el análisis existencial tiene que evitar designar al ente que somos nosotros mismos con expresiones como "vida", "hombre”, "sujeto", "conciencia" o "alma", nombres que designan determinados dominios o sectores de fenómenos temáticamente separables con vistas a determinadas investigaciones en las que no se tienen en cuenta los fundamentos ontológicos:

\footnotetext{
"Una de las primeras tareas de la analítica será mostrar que si se pretende partir de un yo o sujeto inmediatamente dado, se desconoce de forma radical la constitución fenoménica del ser-ahí. Toda idea de "sujeto" - si no está depurada por una previa y fundamental determinación ontológica- comporta ontológicamente la posición del subjectum (hypokeímenon), por más que uno se defienda ónticamente en la forma más enfática contra la "sustancialización del alma" o la "cosificación de la conciencia". La coseidad misma tiene que ser previamente aclarada en su origen ontológico, para que se pueda preguntar qué es lo que debe entenderse positivamente por el ser no cosificado del sujeto, del alma, de la conciencia, del espíritu y de la persona. Todos estos nombres designan determinados dominios fenoménicos "susceptibles de desarrollo", pero su empleo va siempre unido a un curioso no sentir que sea necesario preguntar por el ser del ente así designado. No es, pues, un capricho terminológico el que nos lleva a evitar estos nombres, como también las expresiones "vida" y "hombre", para designar al ente que somos nosotros mismos." (Heidegger, 2003, p. 71).
}

De hecho, Heidegger distingue entre las ciencias o saberes que no se ocupan del Ser, y que se basan en el carácter óntico o existentivo del ser humano, y la Ontología o Filosofía que se ocupa del Ser, y que se basa en el carácter ontológico o existencial del ser humano. Distinción que se explica en los $\S 3$ y 4 de Ser y Tiempo y en el comienzo de "Fenomenología y teología", conferencia pronunciada por primera vez en el mismo año en que fue publicado Ser y Tiempo. Todas las ciencias ónticas son maneras de ser del ser-ahí en las que este se comporta también con relación a entes que pueden ser otros que él. Son así ciencias positivas que tienen siempre como tema un positum, un ente o un ámbito de lo ente que está ahí delante y que de alguna manera ha sido demarcado y fijado como tema de una objetivación y de un cuestionamiento teórico antes de la propia investigación científica. La historia, la naturaleza, el lenguaje o la fe son así objeto de las ciencias históricas, de la Física, de la Lingüística o de la Teología, ciencias ónticas o positivas que se diferencian básicamente entre ellas por el determinado ente o ámbito de lo ente hacia el que se dirigen. Por el contrario, la ciencia del Ser, la Ontología o Filosofía que se desarrollará en Ser y Tiempo, no se dirige hacía ningún ente o ámbito de lo ente, no es positiva, sino que se basa en el carácter ontológico del ser-ahí, en el hecho de que sea afectado por el Ser, y se dirige hacia dicho Ser, diferenciándose radicalmente de todas las demás ciencias. En tanto que ciencia del Ser, la Ontología o Filosofía es la ciencia que se ocupa de la dimensión a partir de la cual aparece cualquier ente o cualquier dato de una ciencia positiva.

La filosofía, ontología fundamental o analítica existencial del ser-ahí, es previa al trabajo positivo de las diversas ciencias específicas que se ocupan del ser humano. Es previa a la Biología, pues el fenómeno "vida" solo puede comprenderse a partir del ser-ahí, es previa a la Antropología, que siempre parte del ser humano en tanto que una realidad dada, y es previa a la Psicología, que se ocupa de los estados mentales del sujeto. $Y$ es precisamente debido a esta prioridad de la ontología existencial del ser-ahí con respecto a los aspectos específicos o existentivos del ser humano que Ser y tiempo no se ocupa de cuestiones como la sexualidad o la política que serían imprescindibles en cualquier estudio antropológico.

La analítica existencial que se va a realizar en Ser y tiempo tiene por lo tanto el objetivo de acceder al ser del ser-ahí para a partir de él elaborar el sentido del Ser en general. Pero Heidegger añade como precisión que para acceder al ser del ser-ahí no podemos par- 
tir de esa cierta precomprensión confusa y poco clara que el propio ser-ahí posee de sí mismo, que posee de su ser. Es porque el ser-ahí posee cierta precomprensión de su ser que podemos interrogarlo sobre ese ser con vistas a explicitarlo, pero no podemos basarnos en esa cierta precomprensión de su ser que posee el ser-ahí para encontrar y explicitar el Ser, pues de hecho esa cierta precomprensión es incorrecta, no alcanza lo esencial, no permite que el ser-ahí descubra su específica constitución de ser. Aunque preontológicamente el ser-ahí no es extraño a sí mismo, pues es consciente de que está afectado por el Ser y se pregunta por él, ontológicamente el ser-ahí está alejado de sí mismo, pues la respuesta que se da a la pregunta por su ser se limita a su dimensión óntica, se circunscribe exclusivamente al ámbito de lo natural o mundano (Heidegger, 2003, p. 40).

En cuanto que posee una dimensión ontológica, en cuanto que es el ente privilegiado, el ser-ahí se interroga por su ser, busca su sentido, pero en cuanto que posee una dimensión óntica, en cuanto que es un ente más entre los entes o elementos del mundo, el ser-ahí posee la tendencia natural a comprender su propio ser a partir del ser de los demás entes que él no es y que encuentra en el mundo. Busca interpretarse a sí mismo a partir de las demás cosas mundanas, como algo meramente presente, manejable o instrumental, y con ello lo único que consigue es comprenderse o interpretarse mal a sí mismo y que su ser, su sentido, permanezca oculto.

Es precisamente por esta incomprensión radical del ser-ahí acerca de su ser que la analítica existencial no puede pasar de la precomprensión ontológica por parte del ser-ahí a la comprensión ontológica propiamente dicha, no puede utilizar ni las categorías de origen óntico ni las respuestas que el ser-ahí encuentra mediante esas categorías. En resumen, la analítica existencial debe ignorar cualquier posible explicación o respuesta óntica que el ser-ahí elabore sobre su ser o sentido último, incluyendo cualquier aportación proveniente de las ciencias positivas o específicas que se ocupan del ser humano, como la Biología, la Antropología o la Psicología, y debe partir exclusivamente de la dimensión ontológica del ser-ahí, del hecho radical y primero de que el ser-ahí existe preguntándose por su ser. Debe partir de la constitución fundamental de su cotidianidad, de las estructuras ontológicas fundamentales y no meramente entitativas o cósicas que el ser humano muestra o expresa en su existencia fáctica, en sí mismo y desde sí mismo (Von Herrmann, 1987, pp. 153-178). En palabras del propio Heidegger:
"Dicho de manera negativa: no se debe aplicar a este ente de un modo dogmático y constructivo una idea cualquiera de Ser y realidad, por muy "obvia" que ella sea; ni se deben imponer al ser-ahí, sin previo examen ontológico, "categorías" bosquejadas a partir de tal idea. El modo de acceso y de interpretación debe ser escogido, por el contrario, de tal manera que este ente se pueda mostrar en sí mismo y desde sí mismo. $Y$ esto quiere decir que el ente deberá mostrarse tal como es inmediata y regularmente, en su cotidianidad media. Y sobre la base de ésta no deberán sacarse a la luz estructuras arbitrarias o accidentales, sino estructuras esenciales, que se mantengan como determinantes de su ser en todo modo de ser del ser-ahí fáctico." (Heidegger, 2003, pp. 40-41).

Pues bien, lo primero que se revela al analizar al ser humano o ser-ahí en cuanto que ontológico o afectado por el Ser es el ser-en-el-mundo (In-derWelt-sein), el hecho de que no es un sujeto aislado en sí mismo, sino que solo tiene subjetividad en cuanto la despliega en su mundo circundante, en cuanto piensa o se ocupa de los demás entes o cosas que le rodean. Al ser-ahí se le ha de ver, pues, en el conjunto de intenciones, significaciones y cosas con las que se relaciona, y a las cosas o entes no hay que tomarlas como cosas en sí mismas, sino como relacionadas con el ser del ser-ahí.

No hay por lo tanto una estricta contraposición sujeto-objeto o conciencia-objeto, un elemento aislado que tiene enfrente, fuera de él, unas cosas totalmente independientes que usa o no, como defiende mayoritariamente el pensamiento tradicional, incluido Husserl, y el propio sentido común, sino una íntima unidad de ambos aspectos denominada seren-el-mundo.

El ser-ahí o ser humano solo puede vivir refiriéndose a los entes que le rodean. Ningún ser humano puede lograr, aunque solo sea por un momento, dejar de pensar en nada o no ocuparse de algo. El ser-ahí está siempre relacionándose con los entes externos, integrándolos en sus propios sentimientos o estados de ánimo (Stimmung), comprendiendo y realizando con ellos parajes o todos de significatividad (bewandtnisganzheit), dando razones, realizando descubrimientos, abriendo posibilidades, proyectando, existiendo, erigiendo el mundo que forma parte de su propio ser. A su vez, todos los entes que rodean a un ser-ahí no son algo por sí mismos, sino que forman parte de los parajes o todos de significatividad que realiza el serahí cuando los abre o hace accesibles, cuando forman parte de los conjuntos de referencia que realiza el ser- 
ahí y que no les son extrínsecos, sino que los constituyen en cuanto útiles, constituyen su ser mismo, les dan un sentido, los convierten en objetos.

El ser-ahí existe dando un sentido o utilidad a los entes que le rodean, convirtiéndolos en objetos manejables e integrándolos en sus centros de interés: el martillo sirve para clavar clavos, y esto le da su identidad, su ser, mientras que los clavos se clavan para colgar un cuadro, que sirve para adornar, para que el ser humano esté a gusto, para que descanse mejor, para que pueda trabajar más, y así hasta donde se quiera. Si no hubiera seres humanos, puede que hubiese algo, no lo sabemos, pues no nos podemos imaginar el mundo sin seres humanos, pero lo que es seguro es que no habría martillos, ni clavos, ni cuadros, pues todo esto son identidades o sentidos que el ser humano otorga a los entes que le rodean cuando los integra en los todos de significatividad o conjuntos de para qué que forman parte de sí mismo, y el último para qué, lo último que le va al ser-ahí, es el cuidado (Sorge) de los entes:

\footnotetext{
"Ser-en-el-mundo, según la interpretación que hemos hecho, quiere decir: absorverse atemática y circunspectivamente en las remisiones constitutivas de la manejabilidad del todo de útiles. El cuidarse de es, en cada caso, como es, sobre la base de una familiaridad con el mundo." (Heidegger, 2003, p. 103).
}

El ser ahí es un ente cuyo ser es posibilidad, ser de una manera o de otra. Encontrándose (Befindlichkeit) en el mundo y comprendiendo (verstehen), se cuida (besorgen) de los entes que le rodean, se preocupa por ellos, e integrándolos en todos de significatividad va más allá de sí y traza metas o posibilidades que luego intenta cumplir. El ser-ahí alcanza así su propia apertura o estado de abierto, abre las posibilidades de su ser y las regula. El ser-ahí existe, se las tiene que ver con el Ser, siendo relativamente al poder ser que es él mismo, como proyecto. Y cuando se comporta de este modo, cuando utiliza los entes que le rodean para trazar metas o posibilidades que luego intenta cumplir, el ser-ahí existe propiamente. No hay un sujeto contrapuesto al Ser, no hay una especie de relación entre el ser-ahí y el Ser, sino que la existencia designa el ser del ser-ahí en tanto que este es un comportarse según el modo de la posibilidad. La relación con el Ser que caracteriza al ser humano no es una simple facultad o un atributo esencial, sino la puesta en relieve de su especificidad, pues sus actos o propiedades son maneras de ser. La esencia del ser humano es al mismo tiempo su existencia. Lo que el ser humano es, es al mismo tiempo su manera de ser o de existir, su manera de ser-ahí, de temporalizarse. No se trata de permanecer en la inactividad o en la contemplación, sino que se trata de vivir trazando posibilidades, asumiendo riesgos, existiendo.

Igualmente, la relación del ser-ahí con sus semejantes, con los otros ser-ahí o seres humanos, también forma parte del ser-en-el-mundo. La relación del serahí con los otros entes que son semejantes a él, que no son útiles manejables, va más allá del cuidarse de ellos (Besorge), es un preocuparse por ellos (Fürsorge) que genera lo social y sus instituciones, y que surge a partir del carácter originario del ser-ahí como ser-con (Mitsein). Pero del mismo modo que el ser-ahí no es un sujeto enfrentado a las cosas objetivas y exteriores, en la relación con los demás no hay dos sujetos tomados simplemente como dos y que estén juntos, un yo que se complete con un tú, sino un ser-nosotros originario. La relación con los otros es tan originaria como la relación con los demás entes meramente presentes y manejables que hay en el mundo, y todos estos elementos que forman la unidad estructural del ser-en-el-mundo son las condiciones fundamentales del propio ser-ahí. El ser-ahí es, existe, encontrándose-comprendiendo y proyectándose más allá de sí mismo, constituyendo su propio "ahí", pero esta actividad se produce en un mundo común, el "ahí" es también el resultado de situaciones compartidas. Aunque es cierto que esta dimensión intersubjetiva se ve fuertemente limitada por el hecho de que la existencia propia o auténtica es finalmente asunto de uno solo, que es cada ser-ahí el que existe proyectándose o cuidándose, mientras que la existencia impropia o inauténtica, la caída, se identifica con las excesivas concesiones a la intersubjetividad. La pertenencia del ser-ahí a sí mismo en su existencia o ser-en-el-mundo es la condición de posibilidad de todo encuentro y de toda relación con los otros.

Concluyendo, lo que afirma Heidegger con el concepto de ser-en-el-mundo es la absoluta respectividad de lo real. No existe nada aislado, todo es respectivo, cualquier elemento está en contacto o relación con otros elementos, constituyendo conjuntos de posibilidades, realizadas o no, que forman parte de las identidades de dichos elementos. No siendo la realidad más que la totalidad de esas redes de relaciones y de las posibilidades que establecen.

No puedo distinguir entre mi yo y la realidad, pues yo estoy en la realidad, yo soy real. Yo poseo una realidad de suyo, soy lo que soy, pero de esta realidad que soy forman también parte todos los demás elementos con los que me relaciono según el modo de la posibilidad. 
Por ejemplo, forma parte de mi realidad la posibilidad de sentarme o no en una silla, y que lo haga o no lo haga, de la misma manera que forma parte de la realidad de la silla, que es lo que es, la posibilidad de que yo me siente o no en ella, y de que lo haga o no lo haga. $\mathrm{Si}$ bien yo, en cuanto que ser humano, mantengo en esa relación mayor iniciativa y soy consciente de ella, por lo que tengo cierta preponderancia, hablo de que integro la silla en el conjunto de relaciones y posibilidades que es mi existencia. Y si bien mi contacto o relación con los otros seres humanos implica mayor significatividad y complejidad que mi contacto o relación con los demás elementos, me afecta en mayor medida.

Con los objetos estoy en contacto o me relaciono, con las demás personas me encuentro. Aunque para Heidegger, a diferencia de los movimientos personalistas y dialógicos, en los que influirá decisivamente, el sujeto mantiene un núcleo de identidad que pese a ser afectado por la relación o encuentro con los demás no se integra con ellos, conservando una especificidad irreductible a la que él se refiere con expresiones como "caída", "cuidado" o "autenticidad".

\section{LA CAÍDA, EL UNO Y EL CUIDADO}

La existencia es el lugar del ser del ser-ahí, el ser humano existe bajo el modo de la posibilidad, trazando metas e intentando cumplirlas. Pero llega un momento en el que el ser-ahí comprende su facticidad, se da cuenta de que él no se ha creado a sí mismo ni tampoco al mundo en el que se encuentra, sino que se halla ahí, instalado, arrojado, sin un fundamento, sin un motivo, y se da cuenta, además, de que él tampoco ha escogido ser cómo es, un ente que existe o se comporta con el Ser a modo de posibilidad, escogiendo unas posibilidades y no otras. Y sin embargo, pese a no haber escogido ser o existir, y pese a no haber escogido su manera de ser o existir, su ser o existir a modo de posibilidad, el ser-ahí se sabe responsable de su ser como si él lo hubiera construido. Comprende que en su existir se juega su ser, que si se equivoca al trazar o al cumplir las posibilidades puede dejar de ser o existir, puede salirse del mundo, puede morir. Se da cuenta de que es responsable de un ser que él no ha creado y que es de un modo que él no ha escogido. Experimenta entonces el estado de ánimo de saberse abandonado a sí mismo, siente angustia (Angst), malestar, desasosiego.

Es precisamente al tratar de evitar la angustia y el malestar cuando el ser-ahí cae, cuando deja de vivir propiamente y escucha lo que el uno (das Man) tiene que decirle. El uno no es alguien en concreto, sino lo otro, el sujeto disipado en la mundanidad, el dejarse llevar por el exterior, por lo que se dice, por lo que se piensa, por lo que no es nadie y somos todos. El uno es lo que podríamos llamar la sociedad, las estructuras que implantan lo que está bien y lo que está mal, lo que se debe y lo que no se debe pensar o hacer. $Y$ sometido al uno, abandonado a la influencia o guía de algo que está fuera de él y que le evita la angustia, el ser-ahí pierde su ser, no en el sentido que se lo quiten, sino en el sentido que ya no es suyo, pues renuncia a plantearse sus propias posibilidades, a comprender e ir más allá de sí, a ser relativamente al poder ser que es él mismo, y acepta como posible lo que el uno dice que es posible, entregado a las habladurías o mero repetir y transmitir lo que se habla, entregado a la avidez de novedades o excitación por lo siempre nuevo y entregado a la ambigüedad o creencia de que se entiende todo cuando en realidad no se entiende nada.

Pero el ser-ahí tiene encomendado su ser, no puede despedir su propio ser ni abandonarlo al uno, es caído cuidante, tiene que cuidarse en medio de la caída, y por eso más tarde o más temprano acaba saliendo del uno y aceptando la angustia que se experimenta en la conducta auténtica de darles un ser o sentido a los entes que le rodean y trazar las propias posibilidades, aceptando la responsabilidad de ese ser propio a modo de posibilidad que ni se ha creado ni se ha escogido, cuidándose de aquello que ha de hacerse. Estructura del cuidado que unifica la pluralidad de modalidades del ser del ser-ahí.

\section{TEMPORALIDAD Y TEMPOREIDAD}

En un primer momento puede parecer que no es posible acceder al ser-ahí en su totalidad debido a que él mismo, al consistir esencialmente en proyectarse en posibilidades, en anticiparse-a-sí, no estaría hecho, acabado, completo. Simplemente, sería un no-estar-todavía-ahí. Por lo cual parecería una empresa desesperada el intentar descifrar en ese ser-ahí inacabado la integridad ontológica de su Ser (Heidegger, 2003, p. 258). Pero esta objeción parte del prejuicio consistente en tratar al ser-ahí como algo dado o presente, como un ente constituido por una serie de elementos cuya suma sería el todo. Ignorando así el rasgo existencial de la anticipación del ser-ahí, reduciéndolo a una mera cosa corpórea compareciente y transponiendo ilegítimamente el acabarse de un ser vivo, la muerte biológica, a la muerte del ser-ahí. Por eso afirma Heidegger la necesidad de que la analítica existencial supere todas las interpretaciones ónticas de la muerte. Frente a la concepción cotidiana de la 
muerte del otro como un terminar o no existir más de un ente que puede ser más o menos sustituible o reemplazable, del que me ocupo un tiempo, y que incluso me puede permitir acceder objetivamente al fenómeno de mi muerte, es necesario mostrar que el difunto es algo más que algo meramente presente o manejable, que sigue perteneciendo a mi estructura de ser-con, que toda muerte la comprendo ontológicamente como cada vez la mía, sin que por ello me sustituya o agote mis posibilidades. Frente a la aproximación meramente biológico-fisiológica de la muerte debe mostrar que aunque la muerte es un fenómeno de la vida, su comprensión ontológica muestra que el morir no es para el ser-ahí un haber llegado a su fin, sino un ser relativamente al fin (kein Zu-Ende-sein sondern ein Sein-zum-Ende). Y frente a la visión teológica de la muerte, la analítica existencial debe reafirmar su sobriedad fenomenológica, su neutralidad respecto a toda moralización del asunto que considera.

Dado que el ser-ahí se las tiene que ver con el Ser, existe, a modo de posibilidad, trazando posibilidades e intentando cumplirlas, tiene una doble relación con el no-ser o nada. No solo se relaciona con la nada en tanto que es un ente arrojado, sin fundamento y sin motivo, y que puede dejar de ser, sino que también se relaciona con la nada en tanto que es fundamento de negatividad. Es fundamento de un no-ser o nada en tanto que toda proyección o posibilidad que tome excluirá lo no proyectado, que al elegir unas posibilidades dejará de escoger otras, que no serán, y está afectado por el no-ser o nada en tanto que siempre elegirá estar o existir en una posibilidad que aún no es:

"El ser-ahí es su fundamento existiendo, es decir, de tal manera que él se comprende desde posibilidades $y$, comprendiéndose de esta manera él es el ente arrojado. Pero esto implica que, pudiendo ser, el serahí está cada vez en una u otra posibilidad, que constantemente no es alguna otra y que ha renunciado a ella en el proyectarse existentivo. El proyecto no solo está determinado por la nihilidad del ser-fundamento en tanto que aquél siempre está arrojado, sino que, incluso como proyecto, es esencialmente negativo." (Heidegger, 2003, p. 303).

Sucede que las posibilidades que el ser-ahí proyecta conciernen a las posibilidades de su ser como un todo que va variando en función de las posibilidades que se cumplen y de las que no se cumplen, de las adiciones. Si el ser-ahí puede captarse a sí mismo como una totalidad es precisamente porque es finito y posee un límite que no puede sobrepasar y que lo completa, porque le espera su propia muerte como posibilidad propia, inevitable e intransferible, porque es seguro que un día morirá. Si el ser-ahí viviese siempre no sería una totalidad proyectante. Es la muerte lo que permite que el ser-ahí se vea a sí mismo como totalidad que existe proyectando posibilidades (Thomä, 1990, pp. 368-428). Y en este sentido el ser-ahí es ser-parala-muerte (Sein zum Tode). Pero esto significa también que la muerte es el límite de esa totalidad que es el ser-ahí, el fin de su ser en el mundo. La muerte no es una posibilidad entre otras del ser-ahí, sino su más peculiar posibilidad, la posibilidad de la más absoluta imposibilidad, la posibilidad tras la cual acecha la nada (Peñalver, 1989, pp. 164-184).

El ser-ahí está insatisfecho en el fondo más originario, pues es doblemente deudor (schuldig). Es deudor en tanto que es fundamento de no-ser o nada, las posibilidades rechazadas, y en tanto que es relativamente a un fin, en cuanto vive la muerte como la posibilidad suprema que le singulariza, que le arranca del uno en el que todas las cosas son substituibles, y que sin embargo es la posibilidad de la imposibilidad, pues es la posibilidad de la nada, y es imposible que la nada sea. La muerte es así la posibilidad más extrema y propia del ser-ahí, y cuando este lo comprende se acepta como pura proyección de posibilidades en camino hacia la posibilidad última y esencial que es su muerte. El ser-ahí considera entonces cualquier otra posibilidad que no sea su propia muerte como simplemente existentiva, renuncia a todo ideal de existencia o posibilidad con un contenido determinado, y con ello se sustrae al dominio del uno y se relaciona propiamente con el Ser.

La muerte es así algo más que un mero fenómeno óntico-biológico, es un fenómeno existencial u ontológico. La lluvia se acaba o se termina, el pan se termina o se consume, mientras que en el ámbito animal o vegetal un simple viviente no muere, sino que "termina", "sale del mundo", "deja de vivir" o "fenece". Sin embargo el ser-ahí, al que le sucede todo eso en tanto que ente, además muere, pues su fin determina intrínsicamente su modo de ser, su existencia, que es algo más que un mero dirigirse hacia su término (Heidegger, 2003, pp. 261-269). En resumen del propio Heidegger proporcionado en una conferencia de 1950 titulada "La cosa", solo el ser humano muere, mientras que el animal termina, no tiene a la muerte como muerte ni delante ni detrás de él. Solo el ser humano es capaz de la muerte como muerte. Pero dado que la muerte es la posibilidad de la nada, y es imposible que la nada sea, resulta que la muerte es la posibilidad de aquello que desde ningún punto de 
vista simplemente es, y por eso la muerte es el cofre de la nada (der Schrein des Nichts), la que alberga en sí lo esenciante del Ser. Y el ser humano, el único ente que se relaciona con la muerte, el único ente que va más allá de los objetos presentes o manejables, de lo existentivo, "es la relación esenciante con el Ser como Ser" (Heidegger, 1994, p. 155).

Es el comprenderse como ser-para-la-muerte lo que permite al ser-ahí decidirse (Entscheidung), relacionarse propiamente con el Ser, existir. Como indica más claramente Heidegger en Kant y el problema de la metafísica, libro publicado en 1929 pero redactado en conexión con Ser y Tiempo, la finitud no es una propiedad accidental del ser-ahí, ni una insuficiencia, sino que es algo originario suyo que está fundamentado en la comprensión del Ser. Por eso al comprenderse como ente deudor arrojado a la existencia y que puede dejar de ser, el ser-ahí comprende el Ser, pues se comprende a sí mismo como ente privilegiado que es o existe, que no es meramente presente o manejable como los demás entes, sino que utiliza a estos entes, los desvela y los incluye en la proyección finita de posibilidades que es su ser o existencia, que al irrumpir de esta manera en la totalidad del ente hace posible el Ser (Heidegger, 1993, p. 192).

Cuando el ser-ahí asume su existencia finita, cuando se sabe libre para la muerte, se sabe también libre con respecto a la contingencia de la circunstancias en las que se desenvuelve y se libera por ello de las ilusiones del uno. Al comprenderse como totalidad que puede salir de la violencia impersonal del uno, pues es él quien va a morir y no el otro o lo comunitario, y al comprenderse también como un ente que ha sido abandonado o arrojado a una existencia temporal que se dirige hacia su fin, el ser-ahí puede entregarse de sí mismo a sí mismo, puede existir explícitamente como proyección creadora, como destino individual (Schicksal):

"Sólo el ser libre para la muerte le confiere al ser-ahí su finalidad plenaria y lanza a la existencia a su finitud. La finitud, cuando es asumida, sustrae a la existencia de la infinita multiplicidad de posibilidades de bienestar, facilidad, huida de responsabilidades, que inmediatamente se ofrecen, y lleva al ser-ahí a la simplicidad de su destino individual. Con esta palabra designamos el acontecer originario del ser-ahí que tiene lugar en la decisión propia, acontecer en el que el serahí, libre para la muerte, hace entrega de sí mismo a sí mismo en una posibilidad que ha heredado, pero que también ha elegido." (Heidegger, 2003, p. 400).
La aceptación por parte del ser-ahí de su existencia fáctica y finita convierte a esta existencia en productiva, permite afirmar su carácter trascendente en tanto que único acceso legítimo al Ser. A partir de la decisión, el ser-ahí existe de una manera libre o propia, se sustrae a las infinitas posibilidades impropias que le ofrece el uno y existe como poder ser o proyección, trazando sus posibilidades propias e intentando cumplirlas, participando de la tarea de hacer posible la verdad y el darse del Ser, lo único que puede dar sentido a su existencia.

Este comportarse con el Ser a modo de posibilidad implica el tiempo, pues en cuanto la existencia del serahí es poder ser, esta existencia no es nunca un simple tener que vérselas con el presente, sino tener que ver con el haber sido pasado y el haber de ser futuro. Todas las estructuras del ser-ahí, unidas bajo la estructura del cuidado, deben concebirse en lo que respecta a su despliegue como temporales. Todo acontece en un único movimiento desglosado en un triple tipo de vivencia o éxtasis, pasado, presente y futuro, que se halla por debajo de todas las demás vivencias: "La totalidad del ser del ser-ahí como cuidado quiere decir: anticiparse-a-sí-siendo-ya-en (un mundo) y en-mediode (los entes que comparecen dentro del mundo)." (Heidegger, 2003, p. 344).

En cuanto el cuidado tiene estructura de posibilidad, su ser es la temporalidad. Y que la temporalidad es el ser del cuidado quiere decir que el ser-ahí es anticiparse a sí (referencia al futuro, al hecho de que el ser-ahí es ser-para-la-muerte y por lo tanto existe trazando posibilidades, proyectándose, y la muerte es su última posibilidad o proyección), siendo ya (referencia al pasado, a la facticidad del ser-ahí, que es o existe sin haberlo elegido y que tiene que trazar o vérselas con posibilidades que de hecho siempre ya han comenzado antes que él), en el mundo en medio de los entes (referencia al presente, al hecho de que el ser-ahí se cuida ocupándose de cosas que siempre se le aparecen como meramente presentes y manejables). Pasado, presente y futuro son las tres dimensiones o éxtasis que constituyen la temporalidad o el sentido mismo del cuidado, el ser del ser-ahí a partir del cual surge la decisión. Si bien hay que distinguir entre la temporalidad originaria y el tiempo vulgar o cotidiano.

La temporalidad (Zeitlichkeit) es la estructura extático-temporal que constituye al ser-ahí en tanto que existe, en tanto que es afectado por el Ser, y en ella predomina el futuro debido a que el ser-ahí es proyección, existe según el modo de la posibilidad. En tanto 
que existe según el modo de la posibilidad, el ser-ahí es temporalización de la temporalidad, es temporal, pero en tanto que ente, el ser-ahí existe además en el tiempo vulgar o cotidiano. El tiempo vulgar es el tiempo del mundo (Weltzeit) que se funda o surge de la temporalidad originaria y se da dentro del mundo. Surge del hecho de cuidarse del ser-ahí, de la necesidad que tiene el ser-ahí de relacionarse con los demás entes mundanos, que solo pueden darse o comparecer como objetos manejables y meramente presentes. Es el tiempo que se concibe como una sucesión de ahoras sin comienzo y sin fin y en la que predomina el presente como ahora puro entre unos ahoras que ya transcurrieron y unos ahoras aún no llegados. Es el tiempo que se mide o representa por el recorrido de las agujas de un reloj, el tiempo del uno o tiempo público que le pertenece a cualquiera y que por lo tanto no le pertenece a nadie, y desde el cual es imposible concretar la existencia del ser-ahí, pues esta es temporalidad o posibilitación originaria que no cae dentro del tiempo vulgar (Greisch, 1994, pp. 319-328 y 418419). Siendo precisamente la caída o abandonarse del ser-ahí en el uno la renuncia a esa temporalidad originaria como proyección en la que consiste su ser y el sumergirse en ese tiempo como mera sucesión de ahoras en el que se hallan los demás entes u objetos.

Finalmente, en tanto que el ser del ser-ahí se define como cuidado que se funda en la temporalidad, se define como existencia histórica. El ser-ahí es decisión proyectante de las posibilidades propias de su existencia, generando la verdad y el "ahí" o mundo en el que se desenvuelve. Pero el ser-ahí no crea sin más la verdad y el mundo con sus proyectos, pues sus actos están siempre limitados por su facticidad, por el hallarse instalado en el seno de unas posibilidades históricas determinadas (Schürmann, 1987, pp. 72-77). Por estar arrojado, el ser-ahí está referido a un mundo y existe fácticamente con otros, es ser-con, relación con los demás ser-ahí. No puede sustraerse al contexto recibido, sino que las posibilidades propias que proyecta tiene que asumirlas siempre desde y contra este contexto. Tiene que aceptar el pasado, el horizonte o destino colectivo (Geschick), para a partir de él generar su horizonte o destino individual (Schicksal) (Heidegger, 2003, pp. 398-407).

Como ya hemos visto, la caída o existencia impropia consiste en perderse en el uno, en comprenderse a sí mismo solo a partir de las diversas posibilidades existenciales de bienestar, facilidad y huida de responsabilidades vigentes en el ámbito público en un momento determinado, y que rápidamente serán substituidas por otras. El ser-ahí que existe impropiamente, sumergido en el uno, vive disperso en una multiplicidad de eventualidades y de circunstancias ante las cuales se ocupa, considerando siempre en primer lugar lo que se hace y lo que de allí resulta, siendo llevado de un lado a otro por sus quehaceres, las empresas, los accidentes y los incidentes. El ser-ahí existe absorto en un hoy inestable en el que comprende el pasado desde el presente, en el que mientras está a la espera de la próxima novedad ya ha olvidado lo antiguo. No se produce entonces la historia, un destino colectivo o fondo ontológico que sirva de horizonte a la existencia, sino un sucederse inconexo de sucesos eventuales dentro del cual el ser-ahí, ciego para las posibilidades, existe de una manera inestable y se dispersa, es incapaz de repetir lo que ha sido, y se limita a retener y a mantener lo que queda de lo que ya ha sido, los restos e informaciones presentes. No habiendo entonces elección real y siendo simplemente zarandeado por las circunstancias y por los acontecimientos.

Pero cuando el ser-ahí se decide (Entschlossenheit), cuando asume sin ilusiones su realidad fáctica, su condición de arrojado y su estructura de negatividad, se proyecta hacia lo ya sido antes de él y lo incorpora a su existencia. Renuncia a comprender el pasado desde el presente y lo comprende desde el futuro, generando una concatenación de la existencia, un horizonte de comprensibilidad a partir del cual son posibles el destino individual y la repetición. Integrado en esta continuidad histórica extensa, en el horizonte colectivo o destino colectivo que son la comunidad y el pueblo, comprende la historia como el retorno de lo posible y se interpreta a sí mismo como historicidad propia, como proyección de posibilidades heredadas-elegidas, generando su horizonte individual y alcanzando a partir de esta fidelidad a sí mismo la estabilidad (Ständigkeit):

"La decisión constituye la fidelidad de la existencia a su propio sí mismo. La fidelidad, en cuanto decisión en disposición de angustia, es, al mismo tiempo, la posibilidad del respeto frente a la única autoridad que un existir libre puede reconocer: frente a las posibilidades repetibles de la existencia. La decisión sería ontológicamente mal comprendida si se pensara que ella sólo es real como "vivencia" mientras "dura" el "acto" de decidirse. En la decisión radica la estabilidad existentiva que, por su esencia, ya ha anticipado todo posible instante que de ella brote. La decisión, en cuanto destino individual, es la libertad para renunciar a una determinada decisión si eventualmente la situación lo demandare. Con ello no se interrumpe la estabilidad de la existencia, sino que, por el con- 
trario, se la confirma en el instante. La estabilidad no se constituye ni por ni a partir de la acumulación de "instantes", sino que éstos brotan de la temporalidad ya extensa de la repetición que venideramente estásiendo-sida." (Heidegger, 2003, p. 406).

Cuando el ser ahí es fiel a su esencia y se decide, se convierte en historicidad propia que comprende la historia como repetición inevitable de las posibilidades de la existencia. Evita entonces disolverse en una mera sucesión de instantes y se sabe libre. Libre no en el sentido de que pueda evitar estar posibilidades, lo que no sería más que una ilusión, sino en el sentido de que en su proyectarse puede renunciar a una determinada decisión si eventualmente la situación lo demandase, en el sentido de que puede no aceptar o no estar de acuerdo con una posibilidad inevitable. Siendo por eso que puede generar su horizonte individual dentro del horizonte colectivo y llevar una existencia estable.

A la conciencia del sujeto trascendental husserliano, que tranquilamente da sentido al mundo, Heidegger opone la existencia trágica de un ser-ahí finito que se halla en el mundo proyectándose, dirigiéndose hacia su fin o muerte, hacia la nada, y cuya única posibilidad de salvación o de sentido consiste precisamente en aceptar o en asumir este hecho, en hacer posible la verdad y el darse del Ser.

Se distingue así la analítica existencial heideggeriana de cualquier religión, aunque en ocasiones parezca que Heidegger haga uso de la experiencia religiosa para describir la estructura existencial del ser-ahí. Frente a cualquier esperanza de redención para el creyente mortal, el ser-ahí está marcado por una incorregible finitud. Finitud que no debe confundirse con la mera mortalidad biológica, pues posee un sentido, pero que designa la esencial dependencia del ser humano de todas las posibilidades abiertas o desocultadas durante su experiencia vital, sin que haya ningún fundamento metafísico o principio que permita al ser humano ir más allá, o independizarse, de la citada experiencia, y sin que, mucho menos, exista ningún tipo de criatura o entendimiento divino que sea fuente última de los fenómenos entre los que se desarrolla la existencia humana.

\section{EL CARÁCTER “MORAL” DE LA DECISIÓN}

Es evidente que esta decisión por la que el ser-ahí supera la caída posee un carácter ético o moral. El ser-ahí se rescata a sí mismo del uno, del estado de alienación existencial en el que no es él mismo, sino en el que vive impropiamente como otro, como uno cualquiera. $Y$ en este sentido Ser y Tiempo puede incluirse en ese movimiento de rechazo de la modernidad surgida de la llustración y de reivindicación de lo específicamente humano del que participan autores tan diferentes como Marx, Nietzsche, Husserl o la escuela de Frankfurt. Si bien Heidegger omite intencionadamente el uso de términos morales para que este acontecimiento se considere adecuadamente como ontológico, originario o existencial, como un momento necesario en el proceso de darse del Ser y de realización del ser-ahí, y no como un acontecimiento concreto existentivo, como la superación por parte del ser humano de una situación contingente o casual que pudiera haberse evitado.

De hecho, pese a su rechazo de la modernidad, Heidegger puede inscribirse en el proyecto moderno de intentar conciliar lo particular o individual y lo universal. Problemática que surge de considerar a cada ser humano como conciencia subjetiva que solo puede determinar sus actos a partir de sus propias estructuras, sin un sistema de fines objetivos, pero que al mismo tiempo admite que dicha subjetividad y su estructura racional solo tiene el estatus de medio o de función al servicio de la reproducción de un proceso que se sostiene a sí mismo y que es indiferente frente a cualquier conciencia subjetiva (Henrich, 1976, pp. 114-117). Enfrentamiento entre la teoría naturalista de la acción y la teoría holista de la sociedad que Heidegger acepta y afronta renunciado a cualquier metafísica de la reconciliación basada en el idealismo, que era la solución propuesta tanto por el marxismo y sus derivados como por el fascismo.

Lo que hace Heidegger es afirmar lo prioritario de la relación del ser humano con el Ser frente a cualquier valor o posibilidad escogida. Lo primero es lo esencial u ontológico, el acontecimiento que permite que se den el Ser y la verdad, que el ser-ahí se decida y se acepte como proyección de posibilidades, mientras que los valores que cada ser-ahí utiliza como criterio o las posibilidades determinadas que elige son secundarias, pertenecen al ámbito de lo fáctico o existentivo, al mundo de los entes.

Se propone así una moral o una ética sin valores. Ningún valor es esencial u objetivo, pues todo valorar se produce en función de los intereses concretos de un sujeto o de una comunidad de sujetos. Cualquier aspecto que se considere como un valor o criterio de decisión, se trate de un aspecto referido a la cultura, al arte, a la ciencia, a la dignidad humana o a la divinidad, es simplemente algo útil para que los seres 
humanos se desenvuelvan y actúen en el ámbito de los objetos y de las finalidades concretas, es algo subjetivo, relativo, discutible.

Lo ente es siempre del Ser, mientras que el Ser es lo que llega a ser lo ente. El Ser es lo que permite la apertura o la proyección como posibilidad, mientras que el ente es lo que se va abriendo o proyectando. Solo es propiamente, solo existe, lo que llega a ser, lo que al abrirse o proyectarse como posibilidad se relaciona con el Ser. Siendo precisamente en esta relación con el Ser, con aquello que tiene por sí mismo un sentido que puede clarificarse (Pöggeler, 1984, pp. 17-20), que el ser-ahí se abre hacia la posibilidad del comienzo originario.

Cuando el ser humano se decide abre su disposición y se convierte en manifestabilidad plena y extrema que realiza sus acciones de una manera creativa e incondicionada, en tránsito a través del cual el Ser en cuanto acontecimiento apropiador despliega su esencia o verdad. Se convierte así en ser-ahí. Se sustrae de la vida técnica y de la historia como cálculo cronológico del objeto previsible (Historie) y se transfigura o transforma en vida proyectiva que efectivamente acontece y que es objeto de la historia efectiva (Geschichte). El Ser o el sentido acontece cuando se produce el acontecimiento apropiador, cuando el ser humano decide vivir como lo que realmente es, como ser-ahí, como finitud proyectante que existe abriendo o desocultando posibilidades, haciendo posible la historia.

La relación con el Ser significa por lo tanto para Heidegger darle la vuelta a la tradicional prioridad metafísica de lo actual con relación a lo posible, de la energeia o acto con relación a la dynamis o potencia (Kearney, 1980, p. 145). Comprendido en su verdad, el Ser es más posibilidad que actualidad, es proyección temporal más que substancia permanente, y en tanto que es en la comprensión o relación originaria con el Ser en donde radica el sentido de la existencia o la esencia del ser humano o ser-ahí, este sentido de la existencia o esencia consiste en la posibilitación, en la capacidad de plantearse posibilidades propias y auténticas e intentar cumplirlas. Por eso: "Por encima de la realidad está la posibilidad" (Höher als die Wirklichkeit steht die Möglichkeit) (Heidegger, 2003, p. 61).
En consecuencia, para Heidegger la moralidad representa un mero fenómeno derivado que presupone el ser deudor originario del ser-ahí (Santiesteban, 2009, pp. 108-109). Lo importante es la llamada de la conciencia originaria del ser-ahí para que se cuide, para que despertando a su ser deudor se comprenda a sí mismo y se haga cargo de sí mismo como poder ser que es siempre, para que elija tener conciencia en tanto que ser libre y abandonando el uno exista a modo de posibilidad, proyectando posibilidades. $Y$ es cierto que a esta exigencia o posibilidad de actuar, de existir, propia o auténticamente, se la podría considerar una moral "originaria" o "primordial" del ser-ahí, pero siempre que quede claro que nos estamos refiriendo a una individualidad honesta y auténtica que a partir de su comprensión y de su aceptación como "ser-para-la-muerte" se sabe totalidad finita o proyecto concreto y asume su responsabilidad para consigo mismo (Vogel, 1994, pp. 24-27). Fundamento ontológico desde el cual el ser-ahí se relaciona con todo lo demás, desde el cual abre o considera todas sus posibilidades de acción, mientras que las instrucciones prácticas que se sigan o los valores que se afronten pertenecerían ya a lo fáctico o existentivo (Heidegger, 2003, pp. 304-306 y 312-313).

Hay así en Ser y tiempo un rechazo de toda concepción teleológica o finalista de la moral, pero también una inversión del deontologismo o teoría del deber de base kantiana, pues cualquier verdad, valor o principio que se intente establecer como criterio de acción, como guía o como meta de conducta, será siempre menos fundamental que el hecho de que el ser-ahí es, existe, relacionándose con el Ser, encontrándosecomprendiendo y proyectándose.

Otra cuestión diferente es la consideración de hasta qué punto esta concepción del ser humano como ente que tiene que tomar sus decisiones a partir de su autenticidad y en un contexto que le es dado permite justificar cualquier decisión tomada, por muy discutible que sea, como sucedió, sin duda, durante el temporal compromiso personal con el nazismo que el propio Heidegger protagonizó apenas cinco o seis años más tarde de la publicación de Ser y Tiempo. 


\section{BIBLIOGRAFÍA}

Greisch, J. (1994). Ontologie et temporalité. Esquisse d'une interprétation intégrale de Sein und Zeit. Paris: PUF.

Heidegger, M. (1977). Sein und Zeit. Frankfurt: Klostermann.

Heidegger, M. (1983). Einführung in die Metaphysik. Frankfurt: Klostermann.

Heidegger, M. (1993). Introducción a la metafísica. Barcelona: Gedisa.

Heidegger, M. (1994). La cosa. En Heidegger, M. Conferencias y artículos. Barcelona: Ediciones del Serbal.

Heidegger, M. (2000). Das Ding. En Heidegger, M. Vorträge und Aufsätze. Frankfurt: Klostermann.

Heidegger, M. (2003). Ser y Tiempo. Madrid: Trotta.

Heidegger, M. (2004). Phänomenologie und Theologie. En Heidegger, M. Wegmarken. Frankfurt: Klostermann.
Henrich, D. (1976). Die Grundstruktur der Modernen Philosophie. En Ebeling, $\mathrm{H}$. (ed.). Subjektivität und Selbsterhaltung. Beiträge zur Diagnose der Moderne. Frankfurt: Suhrkamp.

Kearney, R. (1980). Heidegger, le posible et Dieu. En Kearney, R. y O'Learly, J. S. (eds.). (2009). Heidegger et la question

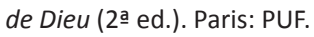

Peñalver, P. (1989). Del espíritu al tiempo. Lecturas de El Ser y el Tiempo de Heidegger. Barcelona: Anthropos.

Pöggeler, O. (1984). Filosofía y política en Heidegger. En Pöggeler, O. Filosofía y política en Heidegger. Barcelona: Alfa.

Richardson, W. J. (1967). Heidegger. Through Phenomenology to Thought (2a ed.). The Hague: Martinus Nijhoff.

Rodríguez, R. (1987). Heidegger y la crisis de la época moderna. Madrid: Cincel.

Santiesteban, L. C. (2009). Heidegger y la ética. México D. F.: Aldus.
Schürmann, R (1987). Heidegger on Being and Acting: from Principles to Anarchy. Bloomington: Indiana University Press.

Thomä, D. (1990). Die Zeit des selbst und die Zeit danach. Zur Kritik der Textgeschichte Martin Heideggers 1910-1976. Frankfurt: Suhrkamp.

Vogel, L. (1994). The Fragile "We". Ethical Implications of Heidegger's Being and Time. Evanston: Northwestern University Press.

Von Herrmann, F. -W. (1987). Hermeneutische Phänomenologie des Daseins. Eine Erläuterung von Sein und Zeit (Band 1: Einleitung: die Exposition der Frage nach dem Sinn von Sein). Frankfurt: Klostermann.

Von Herrmann, F. -W. (2000). Hermeneutik und Reflexion. Der Begriff der Phänomenologie bei Heidegger und Husserl. Frankfurt: Klostermann. 